Reseñas de libros e informes / Books and Reports Reviews

\title{
Ruptura. La crisis de la democracia liberal. Manuel Castells. Madrid: Alianza Editorial, 2017
}

\author{
Iván Federico Basewicz Rojana \\ Facultad de Ciencias Sociales, Universidad de Buenos Aires, Argentina \\ ibasewicz@sociales.uba.ar \\ http://orcid.org/0000-0001-8019-0091
}

"Nuestras vidas titubean en el torbellino de múltiples crisis [...]. Pero aún hay una crisis más profunda, que tiene consecuencias devastadoras sobre la (in) capacidad de tratar las múltiples crisis que envenenan nuestras vidas: la ruptura de la relación entre gobernantes y gobernados" (p. 12). En Ruptura. La crisis de la democracia liberal, el sociólogo y catedrático español Manuel Castells analiza el colapso gradual de la democracia liberal como forma de organización política, lo cual no implica un rechazo abierto hacia la democracia. Este resulta ser un diagnóstico de dimensiones globales que excede las dimensiones propias de cada sociedad. Asimismo, dicho proceso conlleva la aparición de liderazgos políticos novedosos que niegan las formas partidarias existentes, trastocando el orden político vigente.

La obra se estructura en tres segmentos. En la introducción, en el primer y segundo capítulo, se asiste a un momento de presentación de la temática a desarrollar junto con la formulación de un marco conceptual que provea un sustento teórico a la exposición. En tanto, en los capítulos tercero y cuarto son tratados con rigurosidad los siguientes casos: el ascenso de Donald Trump, el proceso iniciado con el Brexit, el fenómeno Emmanuel Macron, la desintegración de la Unión Europea y el fin del bipartidismo español. Por último, en el quinto apartado esboza una reflexión abarcadora de lo expuesto, a la vez que plantea nuevos interrogantes para futuros escritos.

En sintonía con lo anterior, en el primer y segundo apartado, se presentan las nociones teóricas centrales. Estas giran en torno a la noción de crisis de legitimidad política, la cual resulta ser producto de la ruptura del vínculo subjetivo entre los ciudadanos y la clase política, "el sentimiento de que los actores del sistema político no nos representan" (p. 16). Dicha falta de correspondencia debería encontrar su solución en la multiplicidad de opciones y elecciones periódicas que proporciona la democracia liberal. Sin embargo, en tanto toma lugar la profesionalización de la política y la burocratización de los partidos políticos, menos gente confía en este tipo particular de democracia. Igualmente, Castells reconoce que esta problemática remite a un proceso con múltiples actores y de larga duración que, en término último, responde a la globalización como factor causal y a la consecuente limitación de los Estados-nación de dar solución a problemas globales en el medio local. Asimismo, existen factores que dinamizan la crisis de legitimidad como la corrupción política y el terrorismo global, que "conllevó una ola de xenofobia e islamofobia que transformó el escenario político europeo" (p. 33).

Tras estos primeros capítulos de exposición teórica, el autor aboca su análisis al estudio de casos que ejemplifiquen lo anteriormente referido. La desconfianza deriva en la búsqueda de nuevos actores políticos, ya sea encarnado en la figura de un líder 0 de una causa que se muestren contrapuestas a las instituciones deslegitimadas. En este sentido, el primer acontecimiento tratado es el ascenso de Donald Trump a la presidencia de Estados Unidos en 2017, el cual lideró un movimiento de relación directa con el electorado, posicionándose como un candidato anti-establishment frente a una contrin- 
cante como Hilary Clinton de holgados vínculos con los sectores financieros y políticos tradicionales. No resulta posible afirmar un empeoramiento de las condiciones de vida que haya motivado dicha movilización, por lo que la explicación recae sobre la crisis cultural de sectores populares, encabezado por la desintegración social de las comunidades obreras fabriles, frente a un mayor desarrollo de la industria de los servicios. En definitiva, fue electo por "Ios olvidados de la política identitaria: el hombre blanco" (p. 50).

Por otra parte, el caso del Brexit también demuestra ser un caso propicio que da sustento empírico a las afirmaciones teóricas propuestas. En 1975, Reino Unido votó de forma masiva su incorporación a la Unión Europea. Sin embargo, el 23 de junio de 2016 un referéndum vinculante inició el proceso de separación de ella, donde la deliberación electoral tuvo un papel secundario, ya que la campaña "no hizo sino solidificar opiniones ya construidas" (p. 57). El objetivo fundamental perseguido por los promotores de la ruptura fue un movimiento de carácter defensivo contra el proceso de globalización, es decir pretendían una reafirmación de la soberanía nacional. De esta manera, el control fronterizo hizo su aparición para dar respuesta a la competencia laboral y al terrorismo global gracias al rechazo inmigratorio que significaba la medida. Cabe resaltar la situación escocesa, en la cual el voto resultó negativo al Brexitya que Europa representa una alternativa al dominio que ejerce la corona británica en este territorio.

El tercer fenómeno analizado es la aparición del macronismo en el sistema político francés, cuya crisis de legitimidad resulta tan pronunciada como en los casos precedentes. Manuel Castells señala la presencia de dos factores determinantes. Por un lado, "la crisis económica de 2008 y las políticas de austeridad aplicadas por los gobiernos" (p. 67). Por otro lado, el agravamiento de una crisis política preexistente. Esto tras dos presidencias, una de derecha y otra de izquierda, con resultados negativos. El mandato de Sarkozy (2007-2012) "por su arrogancia y desprecio de las formas que se esperan de un presidente" (p. 67) y el de Hollande (2012-2017) "por su indecisión y su autoflagelación" (p. 67). Por ello, el triunfo de Emmanuel Macron es interpretado como un rechazo masivo a los partidos tradiciona- les franceses. Si bien "la democracia liberal obtuvo un respiro, fue el precio del hundimiento del sistema político característico de Francia durante cinco décadas" (p. 69).

El último caso analizado en el tercer capítulo corresponde al de la desunión europea. Sin duda, la construcción de una Europa unida ha sido uno de los proyectos más ambiciosos de las últimas cinco décadas. Ha sido un proceso gradual con límites y fallas en su interior, las cuales han aflorado en la última década. Las mismas pueden resumirse en tres aspectos fundamentales: primero, la falta de una identidad común europea, lo que conlleva a la carencia de un proyecto compartido; segundo, su constitución de arriba hacia abajo, de este modo los países con mayor poderío económico impusieron sus condiciones a otras naciones desfavorecidas generando desigualdades estructurales; por último, las políticas migratorias poco claras, que dieron lugar a crisis de envergadura frente a los grandes movimientos tanto intraeuropeo como extraeuropeo.

Ahora bien, el cuarto capítulo, el de mayor extensión, analiza in extenso la situación española. "En los inicios del tercer milenio, [...] la democracia española presentaba signos de prematuro envejecimiento" (p. 85). La alternancia entre el Partido Popular (PP) y el Partido Socialista Obrero Español (PSOE) dio estabilidad al sistema político español durante cuatro décadas. Sin embargo, durante ese mismo periodo la corrupción se tornó un elemento inherente al sistema partidario. La desconfianza tuvo un marcado aumento a inicios del siglo XXI gracias a dos hechos de envergadura: primero, que la casta política haya imputado, erróneamente, el atentado de la estación Atocha a la organización terrorista vasca ETA; y segundo, la crisis económica de 2008-2010. Al calor de dicho proceso, el 15 de mayo de 2011 tuvo lugar en toda España un movimiento espontáneo y al margen de los partidos políticos y los sindicatos, cuyo hilo conductor fue el rechazo a la representatividad de las instituciones políticas. De esta manera, la democracia era reivindicada mediante actos asamblearios y deliberativos en todo el territorio, siendo que "el impacto de los valores y actores del movimiento transformó el panorama político español" (p. 90). La principal consecuencia de este fenómeno fue la aparición de nuevos actores políticos. Por la derecha, hizo su 
advenimiento Ciudadanos, en tanto que, por la izquierda, Podemos. La emergencia de estos nuevos partidos dio lugar a un cuatripartidismo imperfecto consolidado a partir de las elecciones generales de 2015. De esta manera, el nuevo esquema político derivó en la parálisis del mismo, dada la renovada necesidad de construir alianzas entre actores con divergencias pronunciadas para lograr la conformación de un gobierno. Por último, la importancia de este caso radica en que "el 15-M fue matriz e inspiración de los movimientos sociales en red que se extendieron por Europa, Estados Unidos e incluso América Latina [...] como respuesta a la crisis económica y al hundimiento de la legitimidad política" (p. 121), de ahí la importancia de su tratamiento. A modo de cierre, en el capítulo quinto se esboza una breve reflexión que señala la multiplicidad de formas que la crisis va adoptando. Esto implica un proceso ascendente de la conflictividad y el caos social que muestra indicios de larga duración. "№ detecto señales de nueva vida democrática, más allá de las apariencias. Hay proyectos embrionarios [...] pero no son instituciones estables" (p. 127).

Para finalizar, resulta plausible afirmar que Ruptura. La crisis de la democracia liberal se trata de un texto referencial para los académicos y para los interesados en el amplio campo de la politología y la sociología política, un trabajo que viene a complementar rigurosamente el estudio de un objeto de estudio primario de las ciencias sociales como lo es el Estado. Por ello mismo su lectura y apropiación resulta fundamental para la comprensión de los procesos actuales y la generación de nuevos interrogantes en relación a ellos. 
